$\xi_{p}=$

\title{
Oxygen Reduction Reaction of Carbon Nanotubes Supported Polypyrrole Doped Toluene Sulfonic Acid in Alkaline Medium
}

\author{
Rika Sri Utamii ${ }^{1}$ Wai Yin Wong ${ }^{2}$, Edy Herianto Majlan ${ }^{3}$, Kee Shyuan Loh $^{4 *}$ \\ Fuel Cell Institute, Universiti Kebangsaan Malaysia, 43600 UKM Bangi, Selangor, Malaysia \\ *Corresponding author E-mail: ksloh@ukm.edu.my
}

\begin{abstract}
In this study, polypyrrole/toluene sulfonic acid-based nitrogen doped carbon nanotube (NCNT) is synthesized via chemical oxidative polymerization followed by high-temperature heat treatment under $\mathrm{N}_{2}$ atmosphere. The structure, morphology and composition of the NCNT catalyst are investigated with X-ray diffraction (XRD), scanning electron microscopy (SEM) and Raman spectroscopy. Different $\mathrm{N}$ species including pyridinic, pyrrolic, graphitic, and oxidized-N are quantitatively determined by X-ray photoelectron spectroscopy (XPS). The electrocatalytic activity of NCNT towards oxygen reduction reaction (ORR) in alkaline condition is evaluated with cyclic voltammetry $(\mathrm{CV})$ and rotating disk electrode (RDE). The globular and tubular structure of NCNT can be clearly seen from SEM images. The typical Raman spectrum for NCNT showed two prominent bands around $1348 \mathrm{~cm}^{-1}$ (D band) and $1568 \mathrm{~cm}^{-1}$ (G band). Highresolution XPS spectrum of $\mathrm{N} 1 \mathrm{~s}$ for NCNT showed that graphitic-N has the highest percentage (39.36\%), whereas the pyridinic-N (26.54\%), pyrrolic-N (18.88\%) and oxidized-N (15.22\%). The ORR electrocatalytic activity of the NCNT in $0.1 \mathrm{M}$ KOH has the onset potential of $-0.154 \mathrm{~V}$ vs. $\mathrm{Ag} / \mathrm{AgCl}$, the current density $0.455 \mathrm{~mA} / \mathrm{cm}^{2}$, and electron transfer number of $\mathrm{n} \approx 4$.
\end{abstract}

Keywords: alkaline medium; oxygen reduction reaction; carbon nanotube; polypyrrole; toluene sulfonic acid

\section{Introduction}

Development of new and sustainable energy sources is one of the major topics in recent years due to rapidly growing energy demand and environmental pollution. Currently, fuel cells are considered as one of the cleanest and the most efficient technologies for generating electricity because they can convert chemical energy from fuel into electricity [1]. However, the performance of fuel cells is hampered by the sluggish kinetics of the cathode oxygen reduction reaction (ORR), which cause the low cell potentials [23]. Although Pt has been considered as an effective electrocatalyst for ORR, the cost of $\mathrm{Pt}$ is a major barrier and it suffers from $\mathrm{CO}$ poisoning. Therefore, the development of inexpensive catalysts to replace Pt for fuel cells has attracted great interest in recent years. To replace the precious Pt catalyst, numerous efforts have been made in recent decades [4-8]. Among various candidates, nitrogen-doped carbon nanomaterials, such as carbon nanotube [9], graphenes [10], graphites [11], graphitic [12], and amorphous carbon [13] showed potential as non-metal electrocatalysts for ORR in fuel cells application. Among these carbon nanomaterials, carbon nanotubes (CNT) have been widely used as a non-metal catalyst in fuel cell applications due to high electrical conductivity, good chemical and thermal stability [14]. This high electrical conductivity of CNT can facilitate electron delivery to the active site, making oxygen reduction fast and efficient. In addition, nitrogen-doped CNT has showed a high electrocatalytic activity towards ORR in alkaline medium [6]. Other than that, many researchers found that the bonding configuration of $\mathrm{N}$-atoms incorporated to the surface of carbon materials is important for the electrocatalytic activity towards ORR [15-16]. They also pointed out that the amount of nitrogen in the catalyst material and the nature of nitrogen functionalities are dependent on the nitrogen sources used and the pyrolysis temperature [17-19]. To increase the amount of N into CNT, other heteroatoms such as sulfur (S), boron (B) and phosphorus (P) can be added during the synthesis of NCNT [20-21]. Most studies reported that the ORR activity of the catalyst in alkaline media increases with the addition of S.

Among the nitrogen sources based polymer, polypyrrole (PPy) is the most extensively studied polymer for CNT catalyst due to its high conductivity, high surface area, flexible structure, facile synthesis and excellent environmental stability [22-23]. Furthermore, PPy comprised of nitrogen heterocyclic compound in its structure. While the optimum temperature for heat treatment of $\mathrm{N}$-doped carbon materials is usually carried out between 700 and $1000{ }^{\circ} \mathrm{C}$ [24]. Besides, the ORR activity of N-doped carbons is much higher in alkaline media than in acidic media [14].

In this work, catalysts were synthesized by chemical oxidative polymerization using different composition of polypyrrole (PPy) as $\mathrm{N}$ sources and toluene sulfonic acid $(\mathrm{TsOH})$ as $\mathrm{S}$ source, followed by high temperature heat treatment. The catalysts were characterized using several methods for morphological and chemical composition, and structure. The activities towards ORR in alkaline media were measured using cyclic voltammetry $(\mathrm{CV})$ and rotating disk electrode (RDE).

\section{Experiment}

\subsection{Materials}

Multiwalled carbon nanotube (MWCNT, 90\% carbon basis) was purchased from Sigma Aldrich and treated with nitric acid (purchased from R \& M Chemicals). Pyrrole (Py) was purchased from Merck and used without distillation. Toluene-4- sulfonic acid $(\mathrm{TsOH})$ monohydrate and Iron (III) chloride $\left(\mathrm{FeCl}_{3}\right)$ were pur- 
chased from Merck and used as dopant and oxidant, respectively. Methanol and Nafion (5 wt.\% hydro-alcoholic solution) were purchased from Sigma Aldrich. Concentrated potassium hydroxide $(\mathrm{KOH})$ and Isopropyl alcohol (IPA) were purchased from J. T. Baker and Merck, respectively. All aqueous solutions were prepared using deionized water.

\subsection{Catalyst preparation}

The catalysts were synthesized via in situ chemical oxidative polymerization and high temperature heat treatment. The catalysts were prepared by the following procedure. Firstly, carbon nanotube (CNT, Sigma-aldrich), which was treated with nitric acid, was weight and mixed with $100 \mathrm{ml}$ deionized water and sonicated for $1 \mathrm{~h}$. Then, $0.95 \mathrm{~g}$ of toluene sulphonic acid $(\mathrm{TsOH})$ was added and stirrer for $15 \mathrm{~min}$. After that, $1 \mathrm{ml}$ of pyrrole was added and stirred for $45 \mathrm{~min}$. Then, $\mathrm{FeCl}_{3}(1.14 \mathrm{~g})$ in $10 \mathrm{ml}$ distilled water was slowly added and stirred for $1 \mathrm{~h}$. The product was then filtrated, washed with double distilled water and methanol, and dried in a vacuum oven at $60{ }^{\circ} \mathrm{C}$ for $12 \mathrm{~h}$ to obtain the PPy modified carbon nanotube. Lastly, thermal treatment of the sample was performed in a tube furnace at $700{ }^{\circ} \mathrm{C}$ for an hour under nitrogen atmosphere.

\subsection{Physico-chemical characterization}

The morphology of the as-prepared catalyst samples was investigated using a field emission scanning electron microscope (FESEM, MERLIN COMPACT Zeiss 2013). The crystallographic structure of the catalyst samples was determined using X-ray diffraction (XRD, D8 Advance/Bruker/2009). XRD patterns of the catalysts were performed with scattering angle $2 \theta$ range $20-80^{\circ}$ using $\mathrm{CuK} \alpha$ radiation having wavelength $\lambda=1.504 \AA$. EVA software was used to determine the crystallographic phase associated with the peaks that appear in the XRD patterns. Raman spectroscopy was applied to characterize the structure of the catalysts. Raman spectra were recorded in air using HORIBA Jobin Yvon LabRAM HR $800 \mathrm{UV}$ with a thermoelectrically cooled CCD detector and holographic super-Notch filter. The samples were excited with the $532 \mathrm{~nm} \mathrm{Ar}$ line. The elemental surface compositions of the catalysts were investigated using X-ray photoelectron spectroscopy (XPS). The analysis was carried out using a high resolution Auger electron spectrometer with X-ray photoelectron spectrometer (AES-XPS), model Axis Ultra DLD/Kratos/2009 using $\mathrm{Al} \mathrm{K} \alpha$ radiation. The obtained data were analyzed with CasaXPS 2.3.15 rev 1.3.

\subsection{Electrochemical measurements}

The electrocatalytic activity towards ORR of the catalyst samples were tested in a conventional three-electrode system using an Autolab PGSTAT128N potentiostat. A glassy carbon-type electrode, a Pt wire and an $\mathrm{Ag} / \mathrm{Cl}$ were used as the working electrode, the counter electrode and reference electrode, respectively. Catalyst ink containing $5 \mathrm{mg}$ catalyst, $0.5 \mathrm{ml}$ distilled water, $0.5 \mathrm{ml}$ isopropyl alcohol and $50 \mu \mathrm{l}$ Nafion solution (5 wt \%, Dupont) were ultrasonically mixed for $1 \mathrm{~h}$. Then, $10 \mu \mathrm{l}$ of catalyst ink was pippeted onto glassy electrode $\left(0.1963 \mathrm{~cm}^{2}\right)$, and the electrode was dried in air at room temperature. The electrolyte in each experiment was deaerated with oxygen for $20 \mathrm{~min}$, to prepare an oxygen saturated electrolyte. Cyclic voltammetry (CV) was recorded in the potential range of -1.0 to $0.0 \mathrm{~V}$ at a scan rate of $10 \mathrm{mV} / \mathrm{s}$, and the RDE was recorded at rotation speeds of $400 \mathrm{rpm}, 625 \mathrm{rpm}$, $900 \mathrm{rpm}, 1225 \mathrm{rpm}$ and $1600 \mathrm{rpm}$. All the CV and RDE measurements were performed in $0.1 \mathrm{~mol} / 1 \mathrm{KOH}$.

\section{Results and discussions}

Fig. 1 shows the XRD patterns of the pure CNT and NCNT catalyst. It can be observed that CNT and NCNT catalyst have similar structure. The diffraction peak of NCNT catalyst at $2 \theta$ of about $26^{\circ}, 43^{\circ}, 54.5^{\circ}$ and $78^{\circ}$ are attributed to the carbon structure and corresponding to the graphite structure (002), (100), (004), and (110) respectively [25]. Compared to pure CNT, the NCNT catalyst sample shows lower intensity peak at all diffraction especially at $26^{\circ}$. This indicates that the nitrogen from PPy-TsOH has been successfully doped into CNT. Fig. 2 shows the SEM image for NCNT catalyst. The morphologies of the catalyst are globular and tubular structures that indicate to the polypyrrole and MWCNT, respectively.

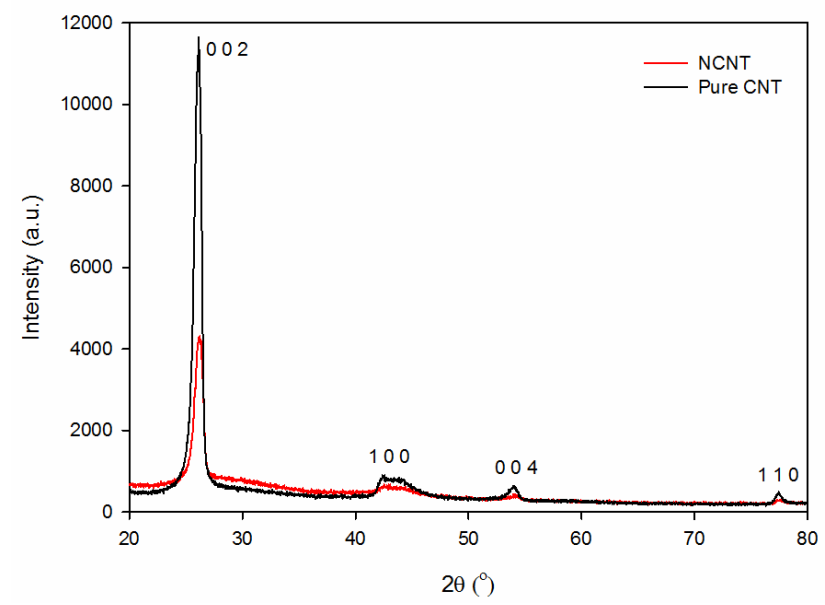

Fig. 1: XRD Patterns of CNT and NCNT

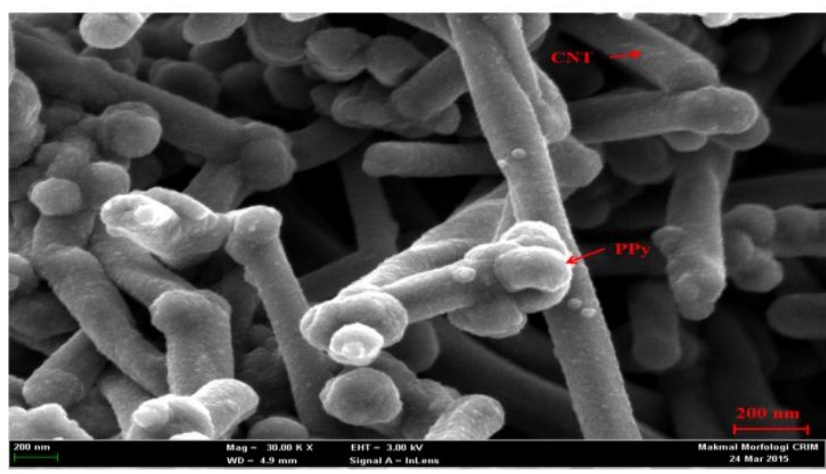

Fig. 2: SEM image of NCNT catalyst

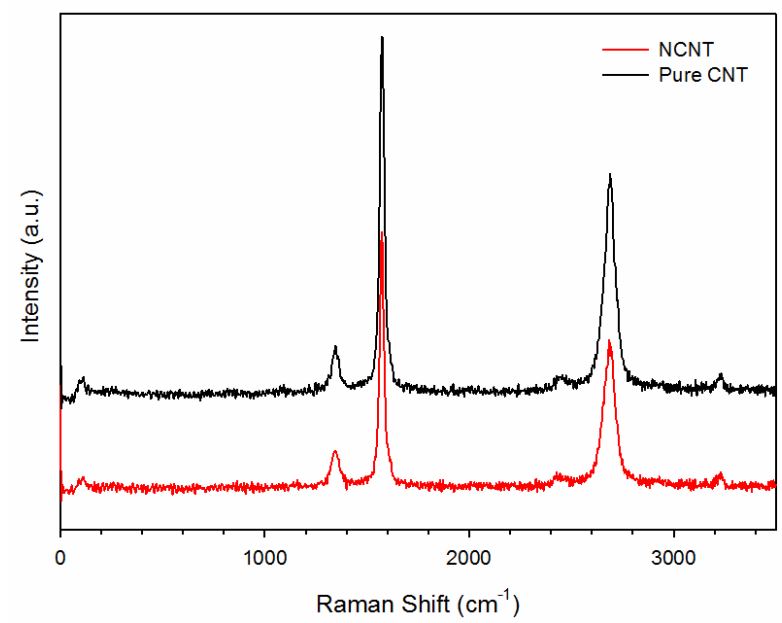

Fig. 3: Raman spectra of CNT and NCNT 


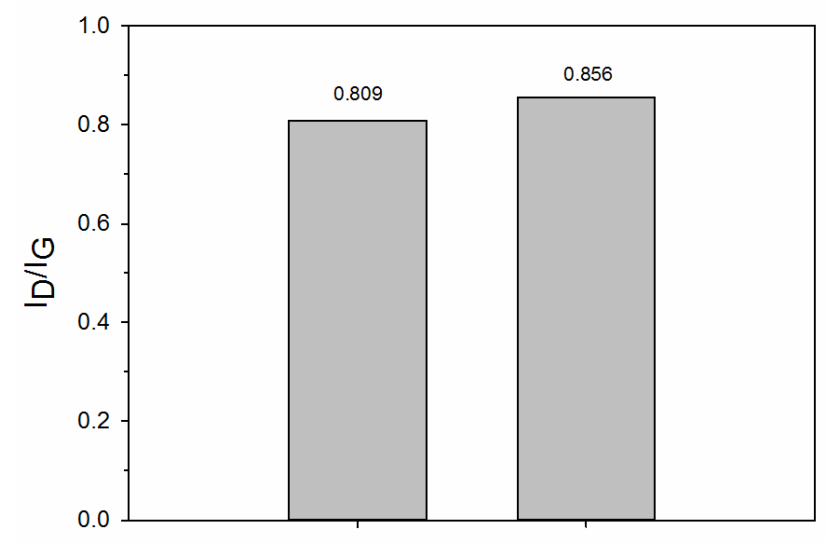

(a)

(b)

Fig. 4: $I_{D} / I_{G}$ ratio of (a) CNT and (b) NCNT

Table 1: Peak of CNT and NCNT

\begin{tabular}{ccccc}
\multicolumn{5}{c}{ Table 1: Peak of CNT and NCNT } \\
\hline Sample & $\mathbf{D}\left(\mathbf{c m}^{-1}\right)$ & $\mathbf{I}_{\mathbf{D}}$ & $\mathbf{G}\left(\mathbf{c m}^{-1}\right)$ & $\mathbf{I}_{\mathbf{G}}$ \\
\hline CNT & 1347 & 203 & 1576 & 251 \\
NCNT & 1344 & 202 & 1567 & 236 \\
\hline
\end{tabular}

Raman spectroscopy is a powerful tool for identifying the structure, disorder, and doping of layer. Fig. 3 shows the Raman spectra of CNT and NCNT catalyst. It can be seen that CNT and NCT have different main peak as shows in Table 1. The amount of defects and the graphitic structure of CNT and NCNT catalyst can be estimated by determining the relative intensity of the $D$ and $G$ bands as shown in Fig. 4. The D band (disorder mode band) is related to the presence of the defects of nanotubes, while the $G$ band is associated with the vibration of $\mathrm{sp}^{2}$-bonded carbon atoms in a graphitic layer [26]. The information about the defect density of the graphite layer structure is given by the relative intensity ratio of the $\mathrm{D}$ and $\mathrm{G}$ bands $\left(\mathrm{I}_{\mathrm{D}} / \mathrm{I}_{\mathrm{G}}\right)$. The defect structure increase as the $\mathrm{I}_{\mathrm{D}} / \mathrm{IG}_{\mathrm{I}}$ increases and therefore the degree of graphitization decreases. As shown in Table 1 and Fig. 4, the $\mathrm{I}_{\mathrm{D}} / \mathrm{I}_{\mathrm{G}}$ ratio of NCNT is higher than pure CNT due to the coating process [27].

The $\mathrm{N}$ element bonding configuration for NCNT catalyst was further investigated by XPS analysis. The XPS survey spectrum of NCNT catalyst (Fig. 5a) shows the presence of atoms C $(85.58 \%)$, $\mathrm{N}(10.06 \%)$, and $\mathrm{O}(4.36 \%)$. The XPS survey spectra for the NCNT catalyst exhibit a predominant C 1s peak at $287 \mathrm{eV}$ and $\mathrm{N}$ 1s peak at $403 \mathrm{eV}$, confirmed the successful doping of $\mathrm{N}$ atoms into CNT. The C 1s spectrum of NCNT catalyst (Fig. 5b) can be described with four different signals at 287.3, 288.0, 289.3, and $292.1 \mathrm{eV}$, indicating the graphite-like $\mathrm{sp}^{2} \mathrm{C}(36.78 \%), \mathrm{N}-\mathrm{sp}^{2} \mathrm{C}$ (33.18\%), N-sp ${ }^{3} \mathrm{C}(14.48)$, and C-O type bond $(15.57 \%)$, respectively [26]. The high resolution XPS spectrum of N 1s for NCNT catalyst (Fig. 5c) reveals the presence of four types of $\mathrm{N}$ configurations at 400.9, 402.2, 403.5, and $405.6 \mathrm{eV}$, which can be attributed to the $\mathrm{N}$ doping in the form of pyridinic-N $(21.88 \%)$, pyrrolic-N (9.97\%), graphitic-N (33.59\%), and oxidized-N (34.74\%) groups, respectively. In addition, the peak of $\mathrm{O} 1 \mathrm{~s}$ (Fig. $5 \mathrm{~d}$ ) originated from $\mathrm{C}=\mathrm{O}(533.2 \mathrm{eV})$ and $\mathrm{C}-\mathrm{OH}$ or $\mathrm{C}-\mathrm{O}-\mathrm{C}$ (534.9 $\mathrm{eV})$ which results from a possible formation of pyridine oxide $\left(\mathrm{N}^{+}-\mathrm{O}^{-}\right)$during the synthesis process [28-29].

The ORR activity of the catalyst was investigated by cyclic voltammetry $(\mathrm{CV})$ in $0.1 \mathrm{M} \mathrm{KOH}$. The measurements were performed in the potential range from 0.0 to -1.0 at scan rate $10 \mathrm{mV} / \mathrm{s}$ and measured in oxygen- and nitrogen-saturated electrolyte. The CV results are plotted in Fig. 6. The position of negative cathodic peak, $\mathrm{E}_{\mathrm{p}, \mathrm{c}}$ is one of the criterion for ORR activity; the higher the ORR activity, the closer $E_{p, c}$ to the thermodynamic potential 1.17 $\mathrm{V}$ [29]. The onset potential, peak maximum, and current density and mass activity of the NCNT catalyst are $-0.154 \mathrm{~V}$ vs. $\mathrm{Ag} / \mathrm{AgCl}$, $-0.277 \mathrm{~V}$ vs. $\mathrm{Ag} / \mathrm{AgCl}$, and $0.455 \mathrm{~mA} \mathrm{~cm}^{-2}$, respectively. In addition, a small peak of the NCNT catalyst can be observed at the potential of about $-0.468 \mathrm{~V}$ vs. $\mathrm{Ag} / \mathrm{AgCl}$ after the maximum reduction current density was reached. Additional active sites can be activated with rising over-potential leading to increasing reduction current.

The NCNT catalysts were also studied by RDE voltammetry in oxygen-saturated $0.1 \mathrm{M} \mathrm{KOH}$ at room temperature with the electrode rotating rates of $400,625,900,1225$ and $1600 \mathrm{rpm}$ and potential scan rate of $10 \mathrm{mV} / \mathrm{s}$. The RDE polarization curves of NCNT catalysts at different rotation rates are shown in Fig. 7. The ORR current density of each catalyst is increase with the electrode rotating speed, due to the faster mass transport. The RDE data can be used to calculate the electron transfer number $(n)$ and the kinetic parameter.

Based on RDE analysis, the electron transfer number $(n)$ of the ORR can be calculated according to the Koutecky-Levich (K-L) equation [30]:

$\frac{1}{j}=\frac{1}{j_{k}}+\frac{1}{B \sqrt{\omega}}$

Where $B$ is the Levich slope which can be further defined as,

$$
B=0.62 n F A C_{0} D_{0}^{2 / 3} v^{-1 / 6}
$$

Where $j$ stands for the limiting disk current density, $j_{k}$ is the kinetic limiting current density, $F$ stands for Faraday constant $(96.485$ $\left.\mathrm{C} \mathrm{mol}^{-1}\right), A$ is the electrode area and $\omega$ is the angular frequency of rotation. The concentration of $\mathrm{O}_{2}\left(C_{0}\right)$, the diffusion coefficient $\left(D_{0}\right)$ of $\mathrm{O}_{2}$ in $0.1 \mathrm{M} \mathrm{KOH}$ solution and the kinematic viscosity $(v)$ of $0.1 \mathrm{M} \mathrm{KOH}$ solution are $1.15 \times 10^{-6} \mathrm{~mol} \mathrm{~cm}{ }^{-3}, 1.95 \times 10^{-5} \mathrm{~cm}^{2} \mathrm{~s}$ , and $0.01 \mathrm{~cm}^{2} \mathrm{~s}^{-1}$, respectively.
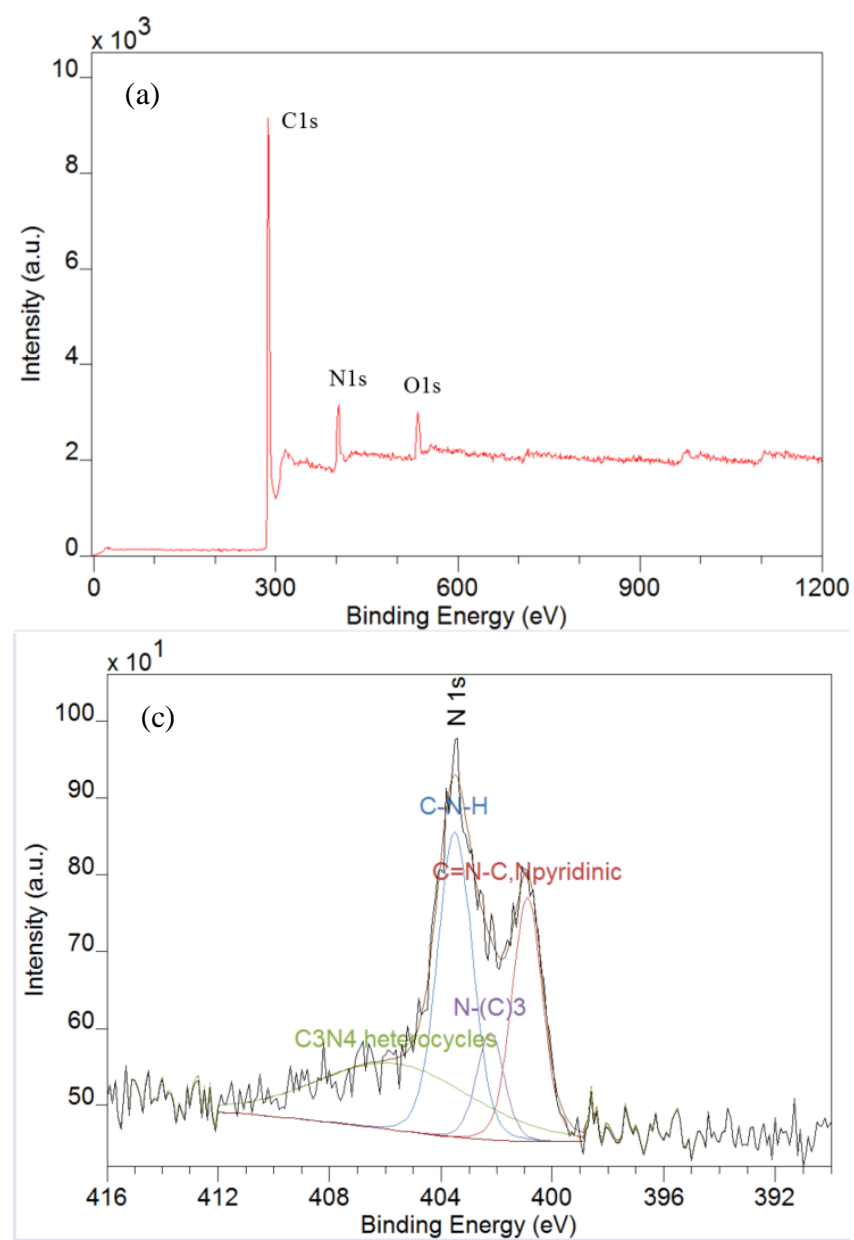

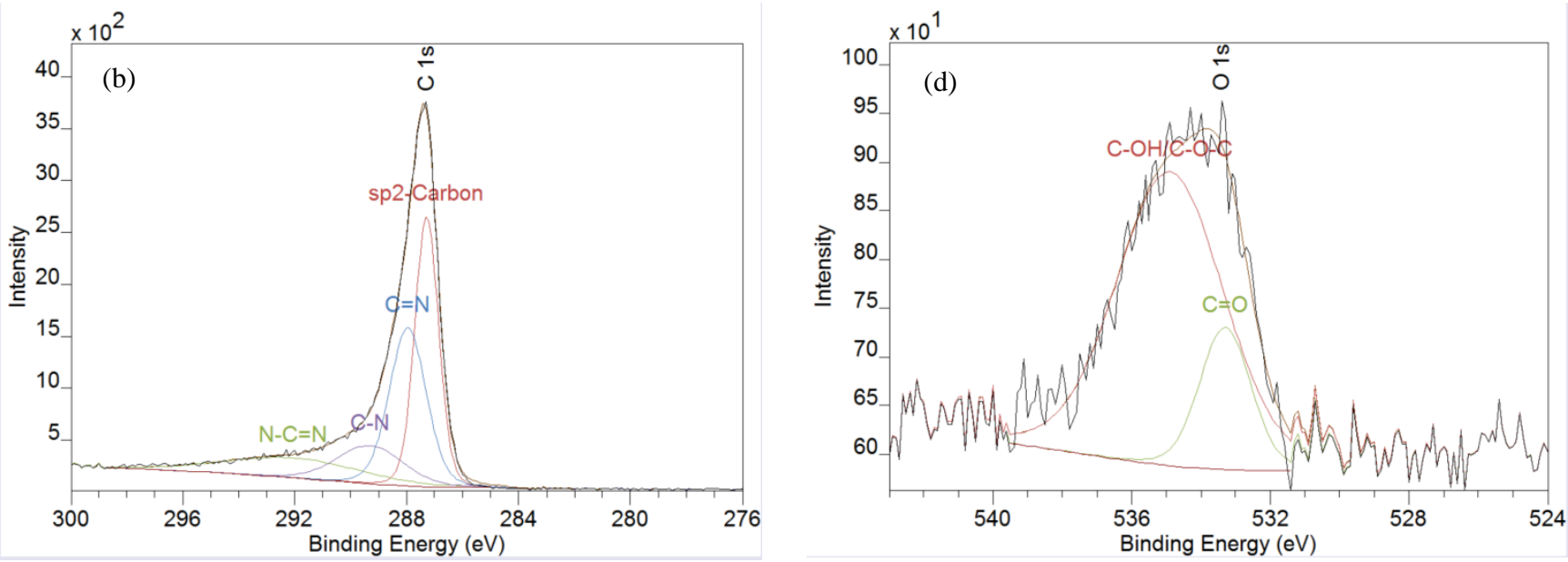

Fig. 5: XPS survey spectra of NCNT catalyst (a), High-resolution XPS of C 1s (b), N 1s (c) and O 1s (d)

Fig. 8 shows the K-L plots of NCNT catalysts at different potentials and rotation speeds. Based on Fig. 8, a linear relation was observed for $j^{-1}$ and $\omega^{-1 / 2}$. The Levich slope of all the NCNT catalysts shows minor variation at applied potentials. Based on the Fig. 8, the electron transfer number $(n)$ and the current density at potential $0.5 \mathrm{~V}$ vs. $\mathrm{Ag} / \mathrm{AgCl}$ are 3.0 and 6.57 , respectively. This indicated that the NCNT catalyst promoted the 4-electron oxygen reduction reaction. The Kotecky-Levich plots at different potential are not necessarily parallel. Parallelism and linearity of KouteckyLevich plots at different potentials indicate that the number of transfer electron does not change in the given potential range. Fig. 8 shows that the slope of the curves changed as the potential changed; indicate that NCNT catalyst has different transfer electron number at different potential. This shows that the NCNT catalyst surface has various active sites with different activities [31].

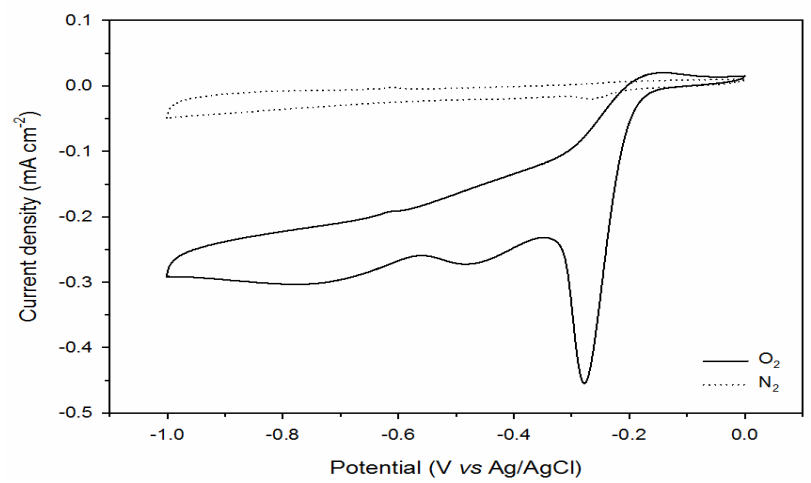

Fig. 6: $\mathrm{CV}$ curves of NCNT catalyst in $\mathrm{O}_{2}$ - and $\mathrm{N}_{2}$-saturated $0.1 \mathrm{M} \mathrm{KOH}$ aqueous solution at scan rate of $10 \mathrm{mV} \mathrm{s}^{-1}$

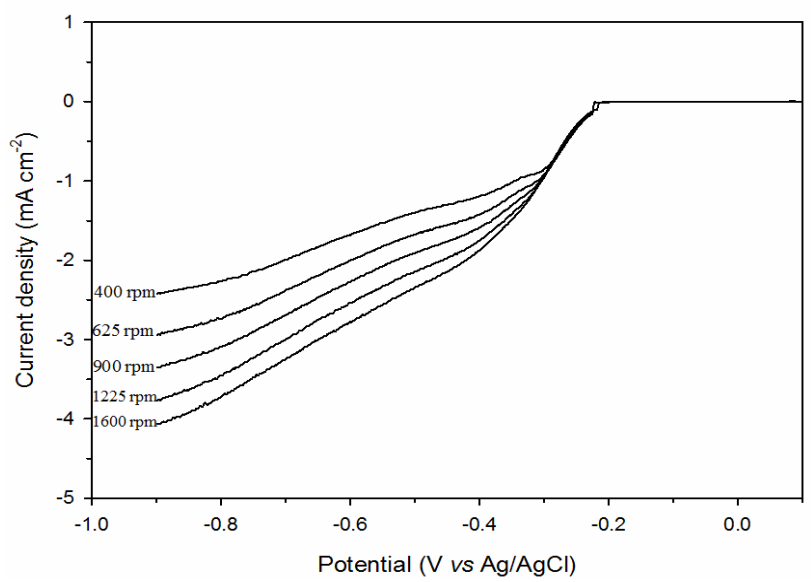

Fig. 7: RDE voltammograms of the NCNT catalyst at potential rate of 10 $\mathrm{mV} / \mathrm{s}$ and various electrode rotating rates

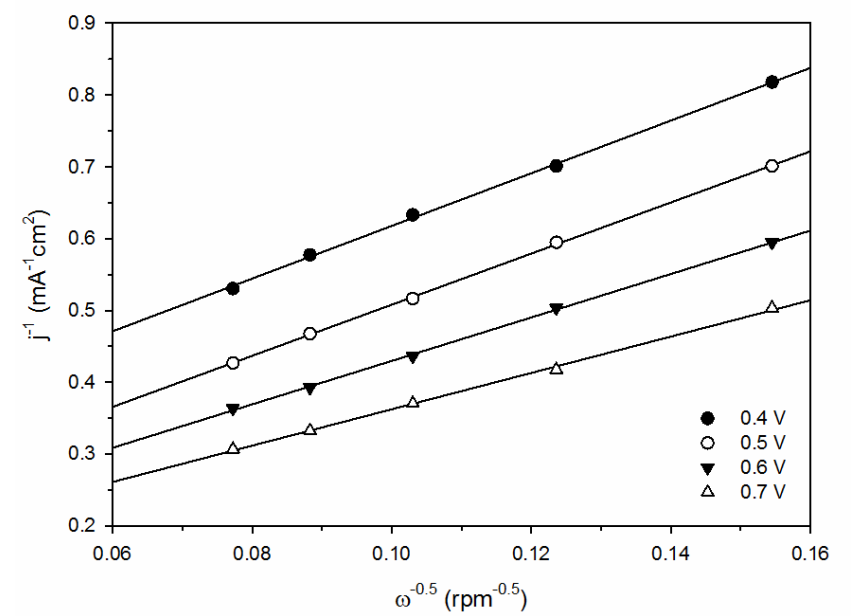

Fig. 8: Koutecky-Levich (K-L) plots of the NCNT catalyst

\section{Conclusion}

Nitrogen and polypyrrole/toluene sulfonic acid doped CNT was synthesized by chemical oxidative polymerization followed by high temperature heat treatment under $\mathrm{N}_{2}$ atmosphere. The SEM studies showed that the morphologies of the catalysts are globular and tubular structure. The $\mathrm{N}$ atomic ratio in the near-surface region was found to be $10.06 \%$ as derived from XPS measurements. The RDE studies revealed the NCNT catalyst promoted the 4electron oxygen reduction reaction.

\section{Acknowledgement}

This study is supported by the University Research Grant with these projects; GUP-2016-038 and DIP-2017-024.

\section{References}

[1] Hoogers G, Fuel cell technology handbook, CRC press, (2014).

[2] Zhiani M, Gasteiger HA, Piana M \& Catanorchi S (2011), Comparative study between platinum supported on carbon and non-noble metal cathode catalyst in alkaline direct ethanol fuel cell (ADEFC). International Journal of Hydrogen Energy 36, 5110-5116.

[3] Salgado JRC, Paganin VA, Gonzalez ER, Montemor MF, Tacchini I, Ansón A, Salvador MA, Ferreira P, Figueiredo FML \& Ferreira MGS (2013), Characterization and performance evaluation of $\mathrm{Pt}-$ $\mathrm{Ru}$ electrocatalysts supported on different carbon materials for direct methanol fuel cells. International Journal of Hydrogen Energy $38,910-920$. 
[4] Song X \& Zhang D (2014), Bimetallic Ag-Ni/C particles as cathode catalyst in AFCs (alkaline fuel cells). Energy 70, 223-230.

[5] Sarapuu A, Samolberg L, Kreek K, Koel M, Matisen L \& Tammeveski K (2015), Cobalt- and iron-containing nitrogen-doped carbon aerogels as non-precious metal catalysts for electrochemical reduction of oxygen. Journal of Electroanalytical Chemistry 746, 917.

[6] Zhao A, Masa J, Schuhmann W \& Xia W (2013), Activation and stabilization of nitrogen-doped carbon nanotubes as electrocatalysts in the oxygen reduction reaction at strongly alkaline conditions. The Journal of Physical Chemistry C 117, 24283-24291.

[7] Wang Y, Sheng ZM, Yang H, Jiang SP \& Li CM (2010), Electrocatalysis of carbon black- or activated carbon nanotubessupported Pd-Ag towards methanol oxidation in alkaline media. International Journal of Hydrogen Energy 35, 10087-10093.

[8] Zhao Y, Zhan L, Tian J, Nie S \& Ning Z (2011), Enhanced electrocatalytic oxidation of methanol on Pd/polypyrrole-graphene in alkaline medium. Electrochimica Acta 56, 1967-1972.

[9] Nxumalo EN, Nyamori VO \& Coville NJ (2008), CVD synthesis of nitrogen doped carbon nanotubes using ferrocene/aniline mixtures. Journal of Organometallic Chemistry 693, 2942-2948.

[10] Lee KR, Lee KU, Lee JW, Ahn BT \& Woo SI (2010), Electrochemical oxygen reduction on nitrogen doped graphene sheets in acid media. Electrochemistry Communications 12, 1052-1055.

[11] Ma Y, Foster AS, Krasheninnikov AV \& Nieminen RM (2005), Nitrogen in graphite and carbon nanotubes: Magnetism and mobility. Physical Review B 72, 205416.

[12] Sevilla M, Sanchís C, Valdés-Solís T, Morallón E \& Fuertes AB (2008), Direct synthesis of graphitic carbon nanostructures from saccharides and their use as electrocatalytic supports. Carbon 46 , 931-939.

[13] Lyth SM, Nabae Y, Islam NM, Kuroki S, Kakimoto M \& Miyata S (2011), Electrochemical Oxygen Reduction Activity of Carbon Nitride Supported on Carbon Black. Journal of The Electrochemical Society $158, \mathrm{~B} 194$

[14] Li H, Liu H, Jong Z, Qu W, Geng D, Sun X \& Wang H (2011), Nitrogen-doped carbon nanotubes with high activity for oxygen reduction in alkaline media. International Journal of Hydrogen Energy 36, 2258-2265.

[15] Wiggins-Camacho JD \& Stevenson KJ (2011), Mechanistic Discussion of the Oxygen Reduction Reaction at Nitrogen-Doped Carbon Nanotubes. The Journal of Physical Chemistry C 115, 20002-20010.

[16] Chen Z, Higgins D \& Chen Z (2010), Nitrogen doped carbon nanotubes and their impact on the oxygen reduction reaction in fuel cells. Carbon 48, 3057-3065

[17] Nxumalo EN, Letsoalo PJ, Cele M \& Coville NJ (2010), The influence of nitrogen sources on nitrogen doped multi-walled carbon nanotubes. Journal of Organometallic Chemistry 695, 2596-2602.

[18] Higgins D, Chen Z \& Chen Z (2011), Nitrogen doped carbon nanotubes synthesized from aliphatic diamines for oxygen reduction reaction. Electrochimica Acta 56, 1570-1575.

[19] Geng D, Liu H, Chen Y, Li R, Sun X, Ye S \& Knights S (2011) Non-noble metal oxygen reduction electrocatalysts based on carbon nanotubes with controlled nitrogen contents. Journal of Power Sources 196, 1795-1801.

[20] Domínguez C, Pérez-Alonso FJ, Al-Thabaiti SA, Basahel SN, Obaid AY, Alyoubi AO, Gómez de la Fuente JL \& Rojas S (2015), Effect of $\mathrm{N}$ and $\mathrm{S}$ co-doping of multiwalled carbon nanotubes for the oxygen reduction. Electrochimica Acta 157, 158-165

[21] Song P, Bo X, Nsabimana A \& Guo L (2014), Additional doping of phosphorus into polypyrrole functionalized nitrogenous carbon nanotubes as novel metal-free oxygen reduction electrocatalyst in alkaline solution. International Journal of Hydrogen Energy 39 , 15464-15473.

[22] Oh HS, Oh JG, Roh B, Hwang I \& Kim H (2011), Development of highly active and stable non-precious oxygen reduction catalysts for PEM fuel cells using polypyrrole and a chelating agent. Electrochemistry Communications 13, 879-881.

[23] Lin Z, Waller GH, Liu Y, Liu \& Wong CP (2013), 3D Nitrogendoped graphene prepared by pyrolysis of graphene oxide with polypyrrole for electrocatalysis of oxygen reduction reaction. Nano Energy 2, 241-248.

[24] Yuan X, Sha HD, Ding XL, Kong HC, Lin H, Wen W, Huang T, Guo Z, Ma ZF \& Yang Y (2014), Comparative investigation on the properties of carbon-supported cobalt-polypyrrole pyrolyzed at various conditions as electrocatalyst towards oxygen reduction reaction. International Journal of Hydrogen Energy 39, 15937-15947.
[25] Xin F \& Li L (2011), Decoration of carbon nanotubes with silver nanoparticles for advanced CNT/polymer nanocomposites. Composites Part A: Applied Science and Manufacturing 42, 961-967.

[26] Yang M, Yang D, Chen H, Gao Y \& Li H (2015), Nitrogen-doped carbon nanotubes as catalysts for the oxygen reduction reaction in alkaline medium. Journal of Power Sources 279, 28-35.

[27] Oh EJ, Hempelmann R, Nica V, Radev I \& Natter H (2017), New catalyst supports prepared by surface modification of graphene- and carbon nanotube structures with nitrogen containing carbon coatings. Journal of Power Sources 341, 240-249.

[28] Mo Z, Liao S, Zheng Y \& Fu Z (2012), Preparation of nitrogendoped carbon nanotube arrays and their catalysis towards cathodic oxygen reduction in acidic and alkaline media. Carbon 50, 26202627.

[29] Sha HD, Yuan X, Li L, Ma Z, Ma ZF, Zhang L \& Zhang J (2014), Experimental identification of the active sites in pyrolyzed carbonsupported cobalt-polypyrrole-4-toluenesulfinic acid as electrocatalysts for oxygen reduction reaction. Journal of Power Sources 255, 76-84.

[30] Qin H, Lao S, Liu Z, Zhu J \& Li Z (2010), Effects of heat treatment on the structure, morphology and electrocatalytic activity of cobalt hydroxide electrocatalyst. international journal of hydrogen energy $35,1872-1878$

[31] Zhao A, Masa J, Muhler M, Schuhmann W \& Xia W (2013), Ndoped carbon synthesized from N-containing polymers as metalfree catalysts for the oxygen reduction under alkaline conditions. Electrochimica Acta 98, 139-145. 